\title{
LY86, LRG1 and PDE9A genes overexpression in umbilical cord blood hematopoietic stem progenitor cells by acute myeloid leukemia (M3) microvesicles
}

\author{
Farnaz Razmkhah ${ }^{1,5^{*}}$ (0), Sorayya Ghasemi ${ }^{2}$, Masoud Soleimani ${ }^{3}$ and Sedigheh Amini Kafi-abad ${ }^{4}$
}

\begin{abstract}
Background: Microvesicles as a new device of cell-cell communication are potentially able to induce some phenotypes and genotypes of an origin cell in a target cell. We evaluate the role of leukemia microvesicles on the leukemia stem cells (LSCs)-specific genes expression in healthy hematopoietic stem progenitor cells (HSPCs).

Methods: HL-60 and NB-4 cell lines were selected for microvesicles isolation by ultracentrifugation. Healthy HSPCS were obtained by magnetic association cell sorting (MACS) and CD-34 micro-beads from umbilical cord blood samples and then, were treated with 20 and $40 \mu \mathrm{g} / \mathrm{ml}$ leukemia microvesicles for 10 days, respectively. LY86, LRG1 and PDE9A genes expression as LSC specific genes were analyzed by QRT-PCR. Surface CD-34 antigen as stemness marker was measured by flow cytometry technique.
\end{abstract}

Results: Healthy HSPCs showed a significant increase in LSC specific genes expression after treatment with both 20 and $40 \mathrm{\mu g} / \mathrm{ml}$ leukemia microvesicles at day 10. All studied groups showed more than 70\% surface CD-34 antigen at the last day of experiment which proved HSPCs stemness.

Conclusion: Our results suggest that healthy HSPCs can be transformed genetically by leukemia microvesicles to over express LSC specific genes. This may be further evidence of leukemia-like transformation by leukemia microvesicles.

Keywords: Microvesicles, Hematopoietic stem progenitor cells, Leukemia, Cell communication

\section{To the respectful editor,}

Microvesicles, as units of biological information, play a remarkable role in cell-cell interactions [1]. Numerous studies have shown that microvesicles are able to phenotypically transform a target cell (normal or tumor cell) to express some proteins [2], mRNAs [3] and microRNAs [4] of origin cell. For example, genomic instability as one of the first events in cancer, can be induced in normal transplant by leukemia microvesicles $[5,6]$. It seems

\footnotetext{
*Correspondence: farnaz_razmkhah@yahoo.com

1 Hematology Research Center, Shiraz University of Medical Sciences, Khalili Street, Shiraz, Iran

Full list of author information is available at the end of the article
}

that microvesicles are passing a crucial step to be known as the first factors in cancer initiation, progression and invasion.

Acute myeloid leukemia (AML) is created from genomic alterations in a healthy hematopoietic stem cell (HSC) which is now called leukemia stem cell (LSC). This new cell keeps the ability of self-renewal but is affected by cell death, proliferation and differentiation [7]. In the leukemia microenvironment, leukemia and healthy cells, are in regular cell-cell communication through microvesicles. This study tries to determine whether leukemia microvesicles are able to affect healthy HSPCs and dysregulate some genes such as LY86, LRG1 and PDE9A as LSC specific genes which have fully different patterns of expression in HSC and LSC [8]. 

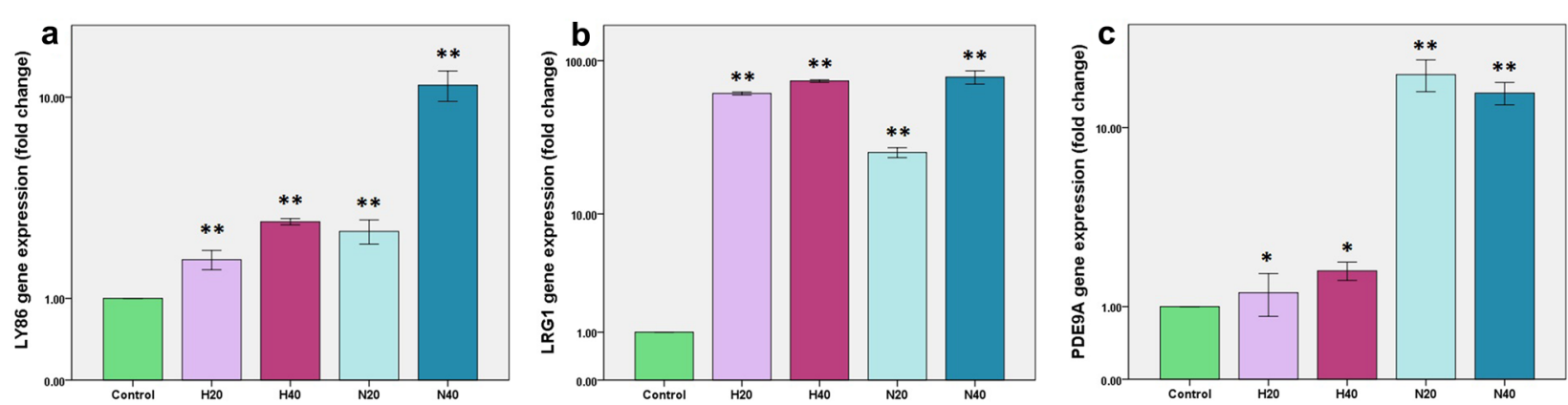

Fig. 1 LY86, LRG1 and PDE9A genes expression in studied groups treated with HL-60 microvesicles (H20:20 $\mu \mathrm{g} / \mathrm{ml}$ microvesicles, H40: $40 \mu \mathrm{g} /$ $\mathrm{ml}$ microvesicles) and NB-4 microvesicles (N20: $20 \mu \mathrm{g} / \mathrm{ml}$ microvesicles, N40: $40 \mu \mathrm{g} / \mathrm{ml}$ microvesicles). a $\mathrm{LY} 86$ gene fold change, $\mathbf{b} L R G 1$ gene fold change and $\mathbf{c}$ PDE9A gene fold change in different groups of HSPCS. ${ }^{*} \mathrm{P}<0.05$, ${ }^{* *} \mathrm{P}<0.001$

Isolated leukemia microvesicles from HL-60 and NB-4 cell lines were assessed by DLS technique (Additional file 1) and showed that all microvesicles are less than $1 \mu \mathrm{m}$ in diameter which is the maximum limit of size for microvesicles (Additional file 2). Then healthy HSPCs from umbilical cord blood samples were treated with 20 and $40 \mu \mathrm{g} / \mathrm{ml}$ leukemia microvesicles for 10 days. CD-34 positive cells $(98 \%)$ at day 0 , still showed a high level of CD-34 antigen (more than 70\%) as stemness marker after 10-day treatment with leukemia microvesicles (Additional file 3).

Quantitative Real Time PCR (Table 1) was performed at day 10 of experiment to evaluate any fold change of three selected genes expression in healthy HSPCs. LY86 gene expression significantly increased $(\mathrm{P}<0.001)$ with both doses of leukemia microvesicles $(20$ and $40 \mu \mathrm{g} / \mathrm{ml}$ ) in both studied groups (treatment with NB-4 and HL-60 microvesicles) as shown in Fig. 1a. LY86 gene overexpression in HSPCs treated with NB-4 microvesicles was more remarkable than in HSPCs treated with HL-60 microvesicles. This change is also dose dependent which is more distinct in HSPCs treated with $40 \mu \mathrm{g} / \mathrm{ml}$ than $20 \mu \mathrm{g} / \mathrm{ml}$ microvesicles.

The fold change of $L R G 1$ gene expression in HSPCs was extremely high in both studied groups $(P<0.001)$. This increase was also dose dependent which was more in HSPCs treated with $40 \mu \mathrm{g} / \mathrm{ml}$ than $20 \mu \mathrm{g} / \mathrm{ml}$ leukemia microvesicles (Fig. 1b).

PDE9A gene expression, however, did not change remarkably in HSPCs treated with HL-60 microvesicles, increased significantly at the last day of experiment (day $10)$ in a dose dependent manner $(\mathrm{P}<0.05)$. This increase was more observable in HSPCs treated with NB-4 microvesicles (Fig. 1c) without a dose dependent manner $(\mathrm{P}<0.001)$.
Table 1 Primer sequences

\begin{tabular}{lll}
\hline Gene name & Primer type & Primer sequence \\
\hline LY86 & Forward & 5-GAA GGA AAG GAG AGC AGA TTT AC-3 \\
LY86 & Reverse & 5-TGA TAG TAG CAT TGG CAC AGG-3 \\
LRG1 & Forward & 5-TCT TGG AGC AGA CAG CGA C-3 \\
LRG1 & Reverse & 5-TTT CGG CAG GTG GTT GAC AG-3 \\
PDE9A & Forward & 5-ATA ACC ACA AGA AGT TGA CTC CTC-3 \\
PDE9A & Reverse & 5-GCA GCT CAG CAT CTC ATT GG-3 \\
HPRT1 & Forward & 5-CCT GGC GTC GTG ATT AGT G-3 \\
HPRT1 & Reverse & 5-TCA GTC CTG TCC ATA ATT AGT CC-3 \\
\hline
\end{tabular}

It seems that microvesicles are powerful enough to affect the pattern of gene expression in a target cell since Cardiomyocytes derived microvesicles/exosomes dysregulated 333 genes in fibroblast including 175 up regulations and 158 down regulations [9]. We previously showed the effect of leukemia microvesicles on survival and transformation of umbilical cord blood HSPCs [1012]. Another study revealed that LSCs microvesicles are able to induce proliferation and migration of myeloid leukemia cells and support malignant cells [13]. In harmony with the above mentioned results, our study showed the ability of leukemia microvesicles in transformation of healthy HSPCs to over express LSC specific genes.

While leukemia microvesicles are able to transform a healthy HSPC through dysregulation of genes, mRNAs, microRNAs and proteins, there is always a question: will this transformation cause leukemia? This question is much more crucial when we know there is a close communication between leukemia and healthy cells in the bone marrow microenvironment through microvesicles. Therefore, any leukemia-like transformation of healthy HSPCs may be a step toward the leukemia, which may result in leukemia progression and relapse. 


\section{Supplementary information}

Supplementary information accompanies this paper at https://doi. org/10.1186/s40164-019-0147-8.

Additional file 1. Materials and methods.

Additional file 2. DLS technique. Isolated microvesicles were quantitatively size proved (80-1000 $\mathrm{nm}$ ).

Additional file 3. CD34 analysis at the end day of experiment. All studied groups expressed more than $70 \%$ stemness marker.

\section{Acknowledgements}

This project was supported by Shiraz University of Medical Sciences.

\section{Authors' contributions}

FR designed the study, did the experiments, prepared the manuscript and analyzed the data; SG supported some materials and critically revised the manuscript; MS designed the study and discussed the data; SAK provided samples and discussed some parts of the data. All authors read and approved the final manuscript.

\section{Funding}

This project was supported by Shiraz University of Medical Sciences.

\section{Availability of data and materials}

The datasets used and/or analyzed during the current study are available from the corresponding author on reasonable request.

\section{Ethics approval and consent to participate}

Not applicable.

\section{Consent for publication}

Not applicable.

\section{Competing interests}

The authors declare that they have no competing interests.

\section{Author details}

${ }^{1}$ Hematology Research Center, Shiraz University of Medical Sciences, Khalili Street, Shiraz, Iran. ${ }^{2}$ Cellular and Molecular Research Center, Basic Health Sciences Institute, Shahrekord University of Medical Sciences, Shahrekord, Iran. ${ }^{3}$ Hematology Department, Faculty of Medicine, Tarbiat Modares University, Tehran, Iran. ${ }^{4}$ Department of Pathology, Blood Transfusion Research Center, High Institute for Research and Education in Transfusion Medicine, Tehran, Iran. ${ }^{5}$ Present Address: Department of Hematology and Blood Transfusion, School of Allied Medical Sciences, Iran University of Medical Sciences, Tehran, Iran.

Received: 5 September 2019 Accepted: 10 September 2019

Published online: 18 September 2019
References

1. Al-Nedawi K, Meehan B, Rak J. Microvesicles: messengers and mediators of tumor progression. Cell Cycle. 2014;8(13):2014-8.

2. Aliotta JM, Pereira M, Li M, Amaral A, Sorokina A, Dooner MS, et al. Stable cell fate changes in marrow cells induced by lung-derived microvesicles. J Extracell Vesicles. 2012;1(1):18163.

3. Bruno S, Grange C, Deregibus MC, Calogero RA, Saviozzi S, Collino F, et al. Mesenchymal stem cell-derived microvesicles protect against acute tubular injury. J Am Soc Nephrol. 2009;20(5):1053-67.

4. Skog J, Würdinger T, Van Rijn S, Meijer DH, Gainche L, Curry WT Jr, et al. Glioblastoma microvesicles transport RNA and proteins that promote tumour growth and provide diagnostic biomarkers. Nat Cell Biol. 2008;10(12):1470.

5. Zhu X, You Y, Li Q, Zeng C, Fu F, Guo A, et al. BCR-ABL1-positive microvesicles transform normal hematopoietic transplants through genomic instability: implications for donor cell leukemia. Leukemia. 2014;28(8):1666-75.

6. Zhang HM, Li Q, Zhu X, Liu W, Hu H, Liu T, et al. miR-146b-5p within BCR-ABL1-positive microvesicles promotes leukemic transformation of hematopoietic cells. Can Res. 2016;76(10):2901-11.

7. Renneville A, Roumier C, Biggio V, Nibourel O, Boissel N, Fenaux P, et al. Cooperating gene mutations in acute myeloid leukemia: a review of the literature. Leukemia. 2008;22(5):915-31.

8. Saito Y, Kitamura H, Hijikata A, Tomizawa-Murasawa M, Tanaka S, Takagi S, et al. Identification of therapeutic targets for quiescent, chemotherapyresistant human leukemia stem cells. Sci Transl Med. 2010;2(17):17ra9.

9. Waldenstrom A, Genneback N, Hellman U, Ronquist G. Cardiomyocyte microvesicles contain DNA/RNA and convey biological messages to target cells. PLOS ONE. 2012;7(4):e34653.

10. Razmkhah F, Soleimani M, Mehrabani D, Karimi MH, Kafi-Abad SA. Leukemia cell microvesicles promote survival in umbilical cord blood hematopoietic stem cells. EXCLI J. 2015;14:423-9.

11. Razmkhah F, Soleimani M, Mehrabani D, Karimi MH, Amini Kafi-abad S, Ramzi M, et al. Leukemia microvesicles affect healthy hematopoietic stem cells. Tumor Biol. 2017;39(2):1010428317692234.

12. Razmkhah F, Soleimani M, Ghasemi S, Kafi-Abad SA. MicroRNA-21 over expression in umbilical cord blood hematopoietic stem progenitor cells by leukemia microvesicles. Genet Mol Biol. 2019;42:465-71.

13. Wang Y, Cheng Q, Liu J, Dong M. Leukemia stem cell-released microvesicles promote the survival and migration of myeloid leukemia cells and these effects can be inhibited by MicroRNA34a overexpression. Stem Cells Int. 2016;2016:1-8.

\section{Publisher's Note}

Springer Nature remains neutral with regard to jurisdictional claims in published maps and institutional affiliations. 